\title{
The stresses of peace-keeping
}

\author{
I.P. Palmer
}

\section{Backeround}

Unlike NHS practice, Army psychiatry is an occupational psychiatric service. This is a description of my three visits to BosniaHertzegovina (BHG) as the visiting Army psychiatrist during 1993.

The primary aims of the deployment of Mental Health Workers to Bosnia were:

(a) to educate personnel of all ranks as to the 'normal' emotional reactions, both in theatre and on return home, following exposure to 'traumatic stress'

(b) to provide debriefing within 48 hours of any 'incident'

The primary role of the psychiatrist is to provide information on the stresses of peacekeeping to the Commanders in Bosnia and $\mathrm{HQ}$ UR. He or she also provides professional superviston for the community psychiatric nurse (CPN) in theatre.

\section{Preparation}

This involved reading voraciously any material about the 'situation', watching TV, listening to the radio news and later, talking to the CPN in theatre on the phone. Prior to my first visit, it was obvious that things were becoming difficult for the resident battalion. The full extent of the atrocities was coming to public attention, culminating in the extenstve coverage of the massacre at a village called Ahnicl.

The Army had a pre-deployment training package which was undertaken on Salisbury Plain. The upshot of the training was a heightened awareness of the threat which thankfully was complemented by an increased confidence in being able to handle possible dificulties.

\section{Deployment}

My first deployment was in early May and within four hours of landing I had started my trip inland. One to two hours took me to

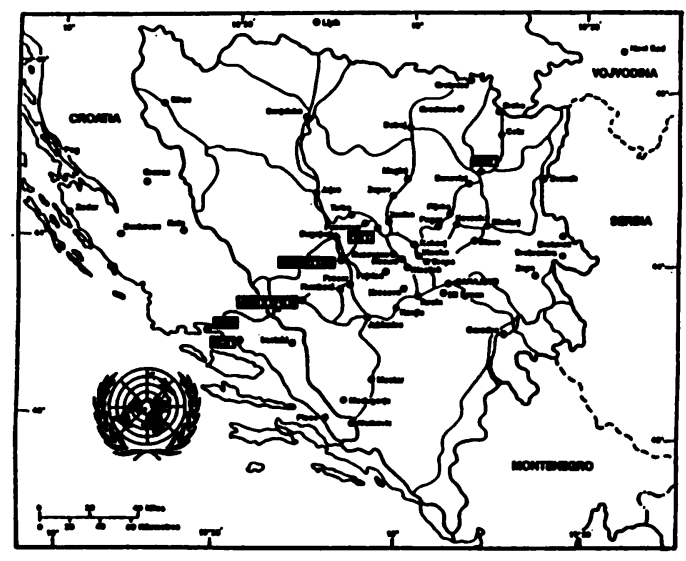

Bosnila and Herzegovina

Tomislavgrad where I spent my first night in 'black-out' conditions. A rather uncomfortable stx hours later I was in Gorni Vakuf.

In Vitez the soldiers were living in Portakabtns which look like little boxes. Officers were billeted in houses rented from various locals. It amazed me to go into the mess and watch satellite TV and to see how quickly those at home could see what was happening, or what the reporters decided was happening.

I spent my first full day with the padre in Gorni Vakuf. We were there to consecrate a plaque on the town bridge to the memory of the first British soldier to be kdlled in BHG. Standing in the rain it was moving to witness a British regiment honour their dead in a foreign place.

A Medical Corps Senior NCO conspired to be my drtver on the return journey from Vitex, as the four to stx hours were spent debriefing him on his experiences, which at one stage included being handed a decapitated child by a distraught mother. It can be quite wearing when, even when you're off duty, you're on duty ! 


\section{BRIEFINGS}

My first impression was that the situation on the ground was not as bad as was portrayed in the media, for soldiers at least. But soldiers are trained to be men of action; here, however, they were not infrequently men of inaction, and at times helpless bystanders.

On my return in July, I was much more aware of the unpredictability of the conflict, in terms of atrocities, and simple things such as provision of electricity and water. In Gorni Vakuf we came under direct fire for the first time. It was my first real experience of being a 'target' and was a strange mixture of excitement and fear. I was reassured to be told "don't worry, you never hear the one that kalls youl"

One night while sitting in the mess with the CPN, we heard a rifle shot from close by. A female interpreter had been targeted by a sniper who had crept up by the mess wall. I offered debriefing to the medics involved which they refused. It reminded me how difficult it is for doctors and nurses to accept psychological debriefing if offered the choice.

Next morning I went out on patrol with the soldiers. They had nicknamed me 'Couch'. The strength and depth of their relationships was impressive. They exhibited a deep and dark humour which never seemed too inappropriate or went too far.

Sitting in the sun I listened to their stories. One lad was still suffering with irritability and hypervigilance following a tour in Northern Ireland months before. How much easier it is to talk to a 'shrink' when he or she is sitting in the back of your tank.

When I returned in September, the situation had deteriorated up country. We could not

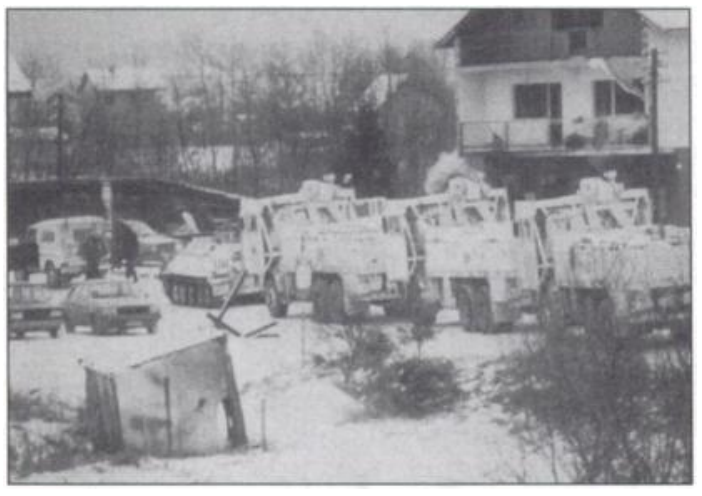

Convoy duties. enter Gorni Vakuf as a tank was shelling the town and we seemed to be surrounded by mortar and small-arms fire. The eventual drtve through the town was more hairy than our previous one.

In Vitez, I worked with liaison officers who were in daily contact with all the main local 'players'. I spent time looking at the various negotiation processes. It was chilling to witness at first-hand the brutal logic and self-interest of the various groups. It was about this time that a large piece of shrapnel missed my occipital lobes by a few centimetres. At the time quite unfrightening, not so later on reflection.

In Sarajevo the awful devastation was deeply depressing. The saddest part were the rows upon rows of children's graves. I accompanied one of the liaison officers involved in the distribution of aid quotas. His tact, diplomacy, flexdbility, honesty and forthrightness commanded the respect of the city elders.

En route back to Vitez our tank broke down. In the stlll of the night I could hear soldiers preparing for a night offensive, an eerie experience. On return to base I found that my bed had been allocated to someone else. I was tired, irritable and angry. I blew my top. I think I had introjected a lot of anger from my colleagues as well as the local Bosnians. Being a member of the 'out-group' was definitely my lot.

In Split I visited a spa hotel/rehabllitation hospital for disabled Croation soldiers. Here, as at the front, men drank heavily and aggresstvely demanded tranquillisers from their GPs. Post-traumatic stress disorder was

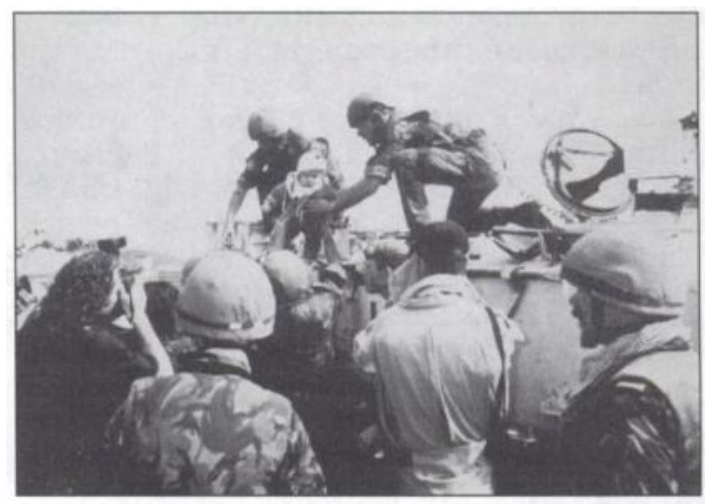

Ald to refugees. 
not recognised or treated psychologically. One can only speculate as to future alcohol and benzodiazepine problems.

Later I spoke with old women 'displaced' from Vosoko who were accommodated in a hotel on the coast. They helped me to realise what the 'land' meant to them. They seemed almost part of it, only to be cruelly wrenched from it and planted in the parched coastline of the Adriatic where so little grows. Here too everyone was 'addicted' to sleeping tablets.

I had been more affected by my visits than I cared to admit, especially the last one. It took me at least two weeks to get round to writing my report. I didn't want to discuss the visit with anyone and felt an outsider at my place of work. I had many disturbing dreams which continue intermittently and revolve around helplessness and being shot at. And I didn't even see anything that could have been described as out of the normal range of human experiencel In fact the whole experience is best summed up as surreal.

\section{Conclusion}

1993 was a year to remember. The experience was extremely valuable for me (and hopefully those with whom I worked). I suspect that this may well be the future of Army psychiatry which will prove stimulating on many levels. There will be the physical, intellectual and emotional challenges posed by such deployments and the chance to help soldiers, local ctvilian faclitities, the UN and other aid agencies to deal with the threats to their mental health posed by such conflicts.

Major I.P. Palmer, Senior Spectalist in Military Psychiatry, Queen Elizabeth Military Hospital, Woolwich SE18 4QH

\section{GMC's guidance on confidentiality}

The General Medical Councll have agreed that part of a letter which they wrote to a member of the College containing their current policy on confidentiality can be published in the Psychiatric Bulletin. This letter was written in response to a specific enquiry.

The Council's guidance on confidentlality distinguishes between disclosures made within health care teams, which relate primarlly to the care and treatment of patients, and those made for other purposes, for example to assist the police or the courts etc. In the former case, doctors should ensure that arrangements are made for patients to be informed, in general terms, about disclosures within health care teams, but they may share any information which members of the team need to know in order to perform their duties. This may, of course, include details of the patient's history.

When disclosures are made for other purposes, the explicit consent of the patient should be sought except in the rare circumstances set out in the Council's guidance. One such circumstance is, where failure to disclose information would place the patient or someone else at risk of death or serious harm. As in other cases, doctors must be able to justify decisions taken on this ground. Disclosure of a patient's medical history may in some cases be necessary and relevant, but doctors must be able to demonstrate that, for example, information they have held for some time gives rise to a risk which had not been apparent earlier.

The Council fully recognises that doctors are often required to make difficult decisions about whether to disclose confidential information about patients without consent. Doctors should give careful consideration to the circumstances of every case in which such decisions must be made and would often be whe to consult their medical defence society or senior colleagues about whether to disclose information, and if so, what form the disclosure should take.

Jane O'Brien, General Medical Councl, 44 Hallam Street, London WIN GAE 